\title{
Antoni Ferrando Francés. Aportacions a l'estudi del català literari medieval, Universitat Jaume I: Castelló de la Plana 2018, 437 pp. ISBN: 978-84- 17429-48-5
}

L'autor ens adverteix a l'avançada que fa una replega de treballs elaborats des del 1989, així com al·lega que estan actualitzats en text i en bibliografia; trets aquests que els atorga renovat interès, malgrat haver-los llegit al seu moment en la font originària.

Altre factor prioritari és que Ferrando concep el llibre com un homenatge a Germà Colón, ${ }^{1}$ fet ben natural considerant la idoneïtat de llurs recerques i el seu reconeixement de la contribució impagable de Colón a la filologia catalana, a pesar d'haver exercit la docència fora de terres catalanoparlants. Aquest deute d'agraïment, que engruna Ferrando al pròleg puntualitzant-lo sobre els 11 treballs seleccionats, fa palès el benefici que s'obté treballant la llengua a través dels textos literaris, així com la lógica coherència que hi ha entre totes dues branques filològiques, la qual mostra també l'obra de Colón, de manera explícita ja en La llengua catalana en els seus textos, del 1978.

Efectivament, per a la filologia en general i per a la crítica literària en particular - i més en concret per als medievalistes - ens ha estat de gran ajuda que als darrers temps grans lingüistes hagin posat el seu objectiu als textos literaris, estenent-se cap a un terreny pràctic i exercint sobre aspectes d'encuny literari un efecte clarificador, el qual és especialment fèrtil al damunt d'obres enigmàtiques; els seus estudis són el que expressa el títol d'aquest llibre: aportacions a l'estudi del català literari medieval. A més, el seu fonament científic, amb incògnites i propostes de caire lingüístic, propicia un avanç i alhora un estímul per a les investigacions d'obres literàries, atraient estudiosos d'altres especialitats. Aquesta reeixida l'han ratificat recentment l'edició de Curial e Güelfa (Ferrando 2007), primmirada des del punt de vista lingüístic, que ofereix una base sòlida per a la novel·la cavalleresca, així com les ingents investigacions

\footnotetext{
1 Figura com dedicatòria: «A Germà Colón, mestre exemplar».
} 
sobre la mateixa obra degudes a l'historiador Abel Soler, les quals n'han significat una renovació.

He d'avançar que alguns capítols del llibre de Ferrando han obert tant camí o són tan densos que es fa costa amunt resumir-los a efecte de ressenyar-los; amb això vull dir que sovint en prenc sols els punts que crec que han influiit més o bé aquells que més m'han copsat o amb els quals puc connectar millor, de la literatura estant.

El primer capítol, «La construcció de la norma cancelleresca catalana», desfà tòpics i enceta línies que cal investigar. Entre els primers s'ha d'esmentar que hom havia fet la llengua de Llull gairebé miraculosa o sortida del no-res. «Hi ha estudiosos de la llengua catalana que han retrotret a Ramon Llull (ca.1232-1316) el privilegi de ser el 'creador de la prosa literària catalana', com si abans d'ell no hagués existit una prosa cancelleresca ja literàriament madura. Els textos administratius, jurídics i historiogràfics anteriors i contemporanis de la seua magna producció literària reflecteixen l'impacte de les pautes lingüístiques de la Cancelleria reial (...). Ben mirat, la prosa de les obres de Llull transmeses en manuscrits més o menys coetanis revela precisament, malgrat les vacil-lacions dels copistes, aquesta influència», p. 18. La racionalització del cas lul·lià la fa, doncs, donant explicació de la seguretat i flexibilitat de la seva llengua a la llum de la prosa cancelleresca; fet al qual cal afegir que la seva biografia (Vita coaetanea) diu que en la joventut ni una mica de gramàtica havia après, ja que accentua aquella influència. Ara bé, al marge del grau de privilegi que se li doni, és un fet que la vàlua quant a la solidesa de la llengua de la seva magna producció literària — com la qualifica Ferrando_- s'ha de rellevar comparativament dins el panorama de les llengües romàniques, sobretot per la primícia del Llibre de Contemplació, com ja va advertir Riquer. ${ }^{2}$

Mèrit així mateix indubtable de Llull entre llengua i literatura — cruïlla que seguirem al llarg de la ressenya d'acord amb l'enfocament del llibre- és d'aplicar el vernacle a la ficció culta en prosa i a la filosofia, mostrant-se veritablement un peoner quant a la seva valoració, la qual continuaran en el segle XIV tot just membres destacats de la Cancelleria barcelonina. És ben coneguda aquesta anticipació lul-liana en l'ús de la llengua vernacla per a matèries elevades - fins i tot respecte a Dante-, com defensa al començament del Llibre del gentil $i$ dels tres savis (1274-83). Així també cal ressaltar la seva precedència pel que fa al camp literari; sovint s'han considerat el Fèlix i el Blaquerna en la prehistòria de la narrativa llarga. I en poesia - sense comptar les obres rimades, construïdes al damunt del suport existent, ni tampoc la mariana, situada entre l'occitana i la popular-, al Cant de Ramon (ca. 1299) Llull inicià ja el canvi de

2 També, actualment, Fernando Domínguez Reboiras: «El texto catalán, por otra parte, ocupa el lugar de honor en la historia de la literatura catalana. Caso prácticamente único en la historia de las lenguas romances, el catalán tiene en los escritos de Raimundo Lulio, y muy especialmente en el Libre de contemplació, un inicio que no deberá aguardar siglos de evolución para obtener su obra maestra. La obra de Lulio explora todas las posibilidades de vocabulario, de estructura gramatical o de recursos estilísticos de la nueva lengua», Soy de libros trovador, Madrid: Sindéresis, 2018, p. 36. 
la llengua poètica, lliure de tot influx trobadoresc (Riquer). ${ }^{3}$ I això —matís d'interès per als que estem capficats en el procés de la llengua o dels orígens de la seva expressió escrita - és adient amb les dades que dóna Ferrando arran d'observar en textos dels darrers decennis del segle XIII que la scripta ja es trobava alliberada del «llast occitanitzant» (p. 20), podent percebre's l'impuls de diferenciació des de començos del mateix segle (p. 19).

Dins del capítol podríem destacar el punt en què s'explica com decaigué la influència estilística de la Cancelleria a conseqüència de la guerra civil del segle XV — com observen ja Riquer i Badia Margarit—, així com la compensació que s'experimentà pel que fa a la preservació de la llengua a causa de l'aparició de la impremta i dels seus efectes. Idea que aclareix els esdeveniments de l'Edat Mitjana ençà, ja que afavorí una proximitat «al model cancelleresc en la llengua administrativa dels segles XVI i XVII». Idees aquestes que s'ampliaran en cloure el llibre, valorant les seves conseqüències.

Com que aquesta línia d'investigació, que podríem remuntar en un sentit ampli, cultural, als Documents per a l'història de la cultura catalana mitgeval (1908) de Rubió i Lluch — que ens aportava encara Riquer a les classes als anys 60 - , té una noble nissaga — passant recentment per Mateu Rodrigo_ ${ }^{4}$ i, com que el treball de Ferrando n'és una fita important des de la perspectiva lingüística actual, ${ }^{5}$ convé puntualitzar els apartats: Llengua cancelleresca, norma cancelleresca. Els tòpics sobre la «prosa cancelleresca» catalana. La singularitat de la scripta catalana al si de la Romània occidental. La formació i l'evolució de la norma cancelleresca catalana. Les bases lingüístiques de la norma cancelleresca catalana. El procés de correcció lingüística. Llengua cancelleresca i prosa

\footnotetext{
3 Sense pretendre un lloc lingüístic ni literari que no li correspongués, a fi d'apreciar els matisos de la seva primeria farem ara un rodeig recordant que la prosa de Bernat Metge sí que s'havia contrastat amb la llengua de la Cancelleria, lògicament sent-ne ell mateix membre rellevant. Ara bé, en el cas metgià, per sobre de les circumstàncies lingüístiques i estilístiques, l'eminència venia ja determinada des dels continguts, car la seva obra és amerada pel corrent humanístic; en Lo somni s'aprecia en el reflex de la sintaxi llatina i el sentit rítmic de la frase (p. 17) i, així, hi ha frases ciceronianes ben vives, imitades i assimilades a la llengua catalana; a més, dins l'epistolografia i l'estil cancelleresc, suraven aleshores les ars dictaminis. L'impuls motor i ennoblidor d'arrel classicista havia apuntat fins i tot a la generació anterior, com palesa el pròleg a la traducció de Pal-ladi — d'interès lingüístic a causa de la pruïja per la llengua (1380-1385)—, obra del seu parastre, el protonotari Ferrer Sayol. El fenomen és semblant a l'italià (Batllori), malgrat la llunyania sociològica i cultural de les respectives cancelleries. Hem arribat fins ací per tal de tornar a Llull, qui, per contra, no comptava amb aquest entorn — tot i que feble_-, car es tractava encara del món i koiné trobadorescos; així doncs, al damunt de la base cultural existent — com puntualitza Ferrando en llengua-, Llull va fer passos de consideració. Passos que després assentarien grans autors; la seva obra hi és al darrere, doncs, com he plantejat des de la literatura a Detrás de los orígenes del Humanismo.

4 Col-lecció de documents de la Cancelleria de la Corona d'Aragó (1291-1420). Textos en llengua catalana, Publicacions de la Universitat de València, 2013.

5 El text original procedeix de Constructing languages: Norms, myths and emotions, Amsterdam /Philadelphia: Johns Benjamin, 2016, pp. 83-98.
} 
literària: compenetració i divergències. ${ }^{6}$ Interès lingüístic de la col·lecció documental de la Cancelleria de la Corona d'Aragó (2013). A tall de conclusió: una norma lingüística al «servey de la Corona d'Aragó».

Faig sobresortir encara dos punts: el primer, l'efecte unificador de la norma cancelleresca, que, front a altres llengües de l'Europa occidental, evità pràcticament la variació diatòpica; l'altre és el referent a la correcció lingüística de les cartes reials gràcies a la formació dels funcionaris i al seu domini de les tres llengües (llatí, català i aragonés). Nivell que així mateix es percep en un altre gènere literari — ressò també d'aquell nucli cultural—: l'oratòria parlamentària; discursos que eren escrits i dels quals ens han quedat mostres - com ara el pronunciat pel rei Martí I a les corts de Perpinyà, en 1406, o el parlament del cardenal Margarit, a Barcelona, en 1454 — que són un testimoni ben eloqüent d'aquella alta categoria.

Al següent capítol es fan unes «Observacions sobre la llengua d'Ausiàs March» (pp. 37-84). ${ }^{7}$ Vegeu la síntesi al començament: «Bàsicament, ens proposem examinar o revisar algunes qüestions relatives al nom, la pàtria i la denominació de la llengua d'Ausiàs March (1400-1459), a la singularitat lingüística i mètrica de les seues poesies i a les possibles causes del seu abandonament de l'occità trobadoresc. Tancarem aquestes observacions amb la presentació d'un breu panorama sobre la percepció linguiística i ideològica de la seua obra al llarg de les èpoques moderna i contemporània», p. 37. Els aspectes de caire més lingüístic (mètrica; alteracions en la transmissió textual...) es desenvolupen amb riquesa i minuciositat, segons és habitual en el professor Ferrando; d'altres, potser més coneguts — com el relatiu al seu nom i al nom de la llengua i de la pàtria del poeta, la construcció de la seva figura com un clàssic o les possibles causes de la seva renúncia a l'occità trobadoresc- ens ofereixen a més un bon resum de l'estat de dits assumptes.

I passem al Curial e Güelfa, el gran text al qual Antoni Ferrando s'ha dedicat tant els últims anys. El primer treball procedeix del recull sobre el Tirant lo Blanc, coordinat per J.-M. Barberà en 1997: «Sobre el marc històric de Curial e Güelfa i la possible intencionalitat de la novel-la» (pp. 85-129). Començava l'autor comparant el pes desigual de les investigacions sobre la novel·la de Martorell en demèrit de l'anònima, bé que avui, degut a la forta embranzida que han experimentat les curialesques no es podria dir el mateix.

Contrastant alguns passatges concrets, com ara el desafiament de Burdeus o la badada del text quant als fills de Pere el Gran, Ferrando ens porta a afrontar les fonts històriques italianes $\mathrm{i}$ les catalanes, $\mathrm{i}$ atenent les hipòtesis crítiques vigents en aquell moment, subratlla la presència de les italianes, cosa que afa-

6 «no es poden confondre prosa cancelleresca i prosa literària; aquesta es deixava influir per la prosa cancelleresca quant a pautes grafiques, morfològiques i sintàctiques i quant a certes innovacions lèxiques, però també exhibia els recursos expressius que aportava el geni creador de cada escriptor», p. 26. (Cfr. la nota 3 supra).

7 El text original procedeix del recull monogràfic sobre Ausiàs March (La poesia d'Ausiàs March i el seu temps, Ricard Bellveser, coord., València: Institució d'Alfons el Magnànim, 2010, pp. 169-229). 
voreix la gestació de l'obra en aquella península; la seva conclusió és que, tot i no ser una obra de propaganda favorable al Magnànim, cal tenir en compte la figura i prestigi del monarca a Itàlia. I havent fet un recorregut pels punts de major interés per a un lingüista, com ara el relatiu a l'onomàstica, tot plegat, Ferrando hi proposa una intencionalitat política: defensar la causa d'Alfons el Magnànim (Curial), tot propugnant una entente amb Roma (la Güielfa); proposta que als darrers temps s'ha vist revifada. Atèn finalment les connexions amb la novel-la caballeresca d'Antoine de la Sale, Le petit Jehan de Saintré, observant seguidament «la singular confluència de l'element provençal, francès, català i italià al Curial» (p. 124).

El següent treball curialenc: «Curial e Güelfa: una història amorosa en clau?», aparegué el 2012 en el recull de Bellveser sobre Dones i literatura. Mentrestant — des de la publicació de l'anterior-s'havia anat intensificant la visió cultural de la novel·la, com fruit d'alta elaboració linguiística i literària, concepció que abans no havia estat generalitzada, considerant-la una part de la crítica una obra amb abundància d'errors o disbarats, propis més aviat d'un context medievalitzant o bé d'un autor amb poca instrucció i escasa exigència. Ací, havent fet atenció a les lectures interpretatives, seguint la línia iniciada de veure-la a l'ombra d'una intencionalitat política i en clau italiana, Ferrando es fixa en dos aspectes: l'heràldica (el lleó i l'àguila / falcó) i la toponomàstica (Melú, Milà, Montferrat). Més endavant està atent a les combinacions de la cronologia de la ficció i la històrica, posició que li porta a fer algunes asseveracions; la principal, que el temps històric afectat pel relat abarcaria des de la máxima tensió per la qüestió siciliana (1268-1285) a la resolució del conflicte pel tractat de Caltabellotta (1302), que afectava a tots els implicats.

I subratlla la visió de l'obra com «una mostra magnífica de la hibridació de la cultura catalana i la italiana en el trànsit de l'Edat Mitjana al Renaixement» (p. 149), així com s'apropa a la idea d'entendre-la com una novel-la en clau, cosa que explica moltes d'aquelles aparents incongruències a què ens hem referit.

Al darrer treball curialenc: «Precaucions metodològiques per a l'estudi lingüístic del Curial e Güelfa», que prové dels volums que Ferrando coordinà arran del «II Encontre Internacional Curial e Güelfa» (2008): Estudis lingüístics i culturals sobre 'Curial e Güelfa' (2012, pp. 31-87), projecta la metodologia linguística vigent sobre el Curial, cas extremament delicat a causa de la seva singularitat lingüística i literària; qualitat que fa extremar les precaucions a l'hora de determinar la coloració diatòpica i l'especificitat estilística, la qual ostenta un nou segell en el terreny narratiu. ${ }^{8}$

Havent passat revista a les diferents aproximacions quant al lloc originari de l'autor, exposa les dificultats inherents al text. I havent vist els punts ineludibles i irreversibles de l'autenticitat del text, aporta dades sobre la transmissió del

${ }^{8}$ De fet, tan sols hi precedí la primor de la prosa del Griselda (Riquer), on sobre l'admiració de les narracions griseldianes precedents, la italiana i la llatina -és a dir, la del Decameró i la del Griseldis-, Metge fa una subtil labor de contrast i d'esmena. 
manuscrit, en bona part degut a la informació que havia proporcionat recentment el makulatur. Precisa la datació del manuscrit a consequiència dels canvis gramaticals en les desinències verbals, constatables pels documents cancellerescos. Continua analitzant la petja del copista; les grafies i la fonètica, la morfosintaxi i la variació dialectal; les preferències lèxiques i els criteris d'orientació diatòpica; el model lingüístic —d'impossible concreció degut a la complaença de l'autor pel polimorfisme de tota mena, que manifesta la seva alta formació i sensibilitat- i, des del pla literari ratifica la ferma assumpció boccaccesca.

La profunditat i el detall d'aquest treball li permeten arribar a destriar les preferències personals de l'autor i la seva consciència lingüística, o bé les variables sociolingüístiques. Apartats com la contraposició de les dades lingüístiques versus els referents culturals contribueixen a obrir camí quant a la procedència geogràfica i la formació cultural de l'autor. A més, en defensa trets com la valencianitat — ja avançada per Colón $-9{ }^{9}$ o un altre molt rellevant per a llengua i literatura: la perfecció de la imitatio, ${ }^{10}$ angle d'observació ben productiu en llengua i en literatura.

I Ferrando gira full amb «La llengua del Misteri d'Elx», publicat en un homenatge a Germà Colón: La Corona de Aragón y las lenguas románicas. ${ }^{11}$ Després del procés de fixació textual i de discutir els problemes de l'anàlisi lingüística, tractant-se d'un text conegut només a través de dues famílies de manuscrits no anteriors a 1625, ofereix una caracterització filològica resituantlo en un espai i un temps de perfil més concret. Per aconseguir-ho fa exercicis comparatistes amb altres textos o estudia les acotacions escèniques, i conclou indicant una proposta de datació, descartant les tesis llemosinistes, que ho posaven abans del segle XV, i les que el situaven en ple XVI. «Si bé la font mediata de Soler (1625) i de l'anònim devot (1639) sembla ser una redacció de la segona meitat del s. XVI — base de la còpia oficial de la Vila d'Elx-, aquesta ha de procedir d'una altra de més antiga, datable a cavall dels segles XV i $\mathrm{XVI}$, que probablement arreplegava part d'un text precedent, posterior si fa no fa a 1450 , i que fou modificat amb nombrosos escurçaments $i$ alguns afegits durant la primera meitat del segle XVI», p. 241.

«Llengua i context cultural al Tirant lo Blanc. Sobre la identitat del darrer Joanot Martorell (1458-1465)» procedeix d'eHumanista 22 (2012). Ens hi exposa un estudi linguiístic sistemàtic del Tirant, cosa que llavors encara no se n'havia fet, probablement per les incògnites que l'envolten quant a l'única o doble autoria, per la llargària i complexitat de la narració, amb abundància de

9 No vol dir això que sigui necessàriament de procedencia valenciana, però sí amb certa vinculació amb València (p. 217).

10 Aquest darrer tret, així com bona part de les consecucions ferrandianes - com ara el gran valor i riquesa del text, la preponderància dels trecentistes italians, una intencionalitat amagada o la perspicàcia d'una política al darrere_ s'adiuen amb l'orientació dels meus primers treballs, que daten de finals del decenni del 80 . Val a dir, podem comprovar que, malgrat les dissemblances entre l'enfocament i el tractament de llengua i literatura, totes dues branques, no van en direccions oposades.

11 G. Holtus, G. Lüdi \& Metzeltin (eds.), Tübingen: Gunter Narr Verlang (1989), pp. 75-89. 
registres lingüístics, o per la dificultat d'una edició filològica i crítica amb fixació del text. Amb tot, a les conclusions Ferrando ha de deixar-hi qüestions obertes (pp. 297-299).

Donem els títols dels capítols i subcapítols: 1. La llengua del Tirant lo Blanc. 1.1. La complexitat lingüística del TB: la mà de Martorell i la 'intervenció progressiva' de Galba. 1.2. Dues scriptae al TB? 1.3 L'ombra allargada de Joan Roís de Corella. 2. La qüestió de l'autoria del TB i de la identitat del darrer Joanot Martorell. 2.2. Les hipòtesis: tres Joans Martorells i tres escenaris de redacció: Barcelona, Dénia i València ${ }^{12}$. 2.2.1. La hipòtesi de l'escrivà de ració del Primogènit: un constructe ideològic? 2.2.2. La hipòtesi del procurador del comte de Dénia: una bona argumentació no suficientment provada. 2.2.3. La hipòtesi del Joanot Martorell en contacte directe amb Joan Roís de Corella i Jaume de Vilaragut: entre la força dels indicis documentals i la seducció de les intuïcions. ${ }^{13}$

Els tres treballs següents són plenament valencians. El primer, «Les relacions literàries de Joan Roís de Corella» (Afers 76, 2013, pp. 635-659) presenta especial interès sociològic per tal com Corella es trobava en el centre de la vida cultural valenciana de les quatre darreres dècades del Quatrecents. Estudis posteriors a aquest treball van completant la seva figura tot corroborant aquesta idea; així, la tesi de Vicent Garcia Peris sobre el llibre Primer de la traducció corellana de la Vita Christi de Ludolf de Saxònia (2015), que ha seguit avançant des de vessants teològics i traductològics. ${ }^{14}$

Ferrando s'endinsa als temes principals, com ara les amistats jovenívoles i els cercles literaris; el cercle de lletraferits de la casa de Berenguer Mercader i els contactes cortesans, i la seva relació amb el cercle de Fenollar; així com estudia les dedicatòries, els colofons i la labor oratòria, considerant-los indicadors dels seus contactes socials, i ho fa notant amb especial atenció la imitatio corelliana. ${ }^{15}$ Tots aquests ítems li porten a entendre millor l'impacte de la figura de Corella a causa de la seva projecció pública, fins i tot per sobre de la

12 Les tesis corresponen respectivament a Jaume Torró, Agustín Rubio Vela i Abel Soler, i es desenrotllen en el següents apartats.

13 Segons Ferrando, la darrera interpretació dels fets, per part de Soler, no exempta d'incògnites, sembla harmonitzar interrogants de les dues primeres tesis, que queden excloses; però presenta llacunes a documentar. En realitat és la tesi tradicional enriquida amb noves suggerències; la seva proposta, a l'entorn dels Vilaragut — dada ja intuïda per Riquer-, té cops brillants, com el nom de Carmesina, que correspon al d'una criada molt beneficiada per l'amo Vilaragut. Sobre aquesta idea, que lliga molt bé amb la barreja d'història i ficció humorística, típica d'aquesta novel-la caballeresca, Soler publica en 2013 El corsari Jaume de Vilaragut i la donzella Carmesina. El cavaller que inspirà el «Tirant lo Blanc.

14 Heus ací un exemple pres del final de la Introducció de dita tesi: «L'anàlisi de la traducció es clou, finalment, amb un apartat dedicat a l'estudi dels passatges de carácter contemplatiu, que aporten el major grau d'originalitat a la traducció, i ens revelen un Roís de Corella ben coneixedor de la técnica franciscana de meditació, que aclimata el seu trasllat als gustos dels seus lectors i a les característiques espirituals de la cultura receptora.»

15 Recurs, per cert, típicament humanístic, sobre el qual tenen un camp molt ric els lingüistes comparant la sistemàtica entre diferents autors. 
literària. Té present així mateix la petja de la Inquisició, car bé que no li va afectar de manera física, sí que el va pressionar; encara que ignorem fins a quin punt arribà a fer emmudir el que fou un veritable líder literari i religiós a la València de l'època.

Hem de destacar el treball «Sobre una etiqueta historiogràfica de la literatura catalana: la 'valenciana prosa'» pel que fa a la claredat d'idees exposades en un moment (1993; dins Caplletra 15) en què s'utilitzaven els conceptes relatius a aquesta prosa quatrecentista amb molta imprecisió. Comença per l'aclaració del sintagma «valenciana prosa» arran de les ocasions en què s'usà i segueix per les interpretacions de la historiografia literària contemporània, donat que grans figures de la crítica (Jordi Rubió, Joan Fuster, Sanchis Guarner) hi entraren en la problemàtica amb matisacions diverses; ell reforça la posició de Colón quant a la significació com 'idioma, llengua', tot i que a vegades sembli al-ludir a una pruiija estilística.

En aquesta conjuntura, Ferrando analitza la terminologia estilística de l'època en els diferents autors (Corella, Miquel Peres, Felip de Malla...), arribant a l'evidència que «els coetanis no disposaven d'un nom específic per a designar aquell estil» (p. 351), fet que li porta a concloure que «valenciana prosa» no era el nom de cap estil, ans una forma cultista de dir 'llengua valenciana'. Cal tenir present, doncs, que tot i que resulti còmode recórrer al sintagma - i molts hi hem recorregut alguna vegada-, no és aconsellable, perquè — raona assenyadament — «perpetua uns prejudicis ideològics, una visió fragmentària de la literatura catalana i una interpretació estilística d'una mera fórmula cultista que no s'adequa als fets historicoliteraris. En canvi, un qualificatiu com artitzat satisfà millor les exigències de rigor històric i científic» (p. 357). ${ }^{16}$

En «Llengua i espiritualitat en la Vita Christi d'Isabel de Villena» (Scripta, 2015, pp. 24-59), observa com sor Isabel pretén promoure l'afecte religiós de les seves monges i com al seu text obtenim alhora un retaule de la refinada cultura d'aquell moment. Text el de sor Isabel interessant, doncs, no sols per permetre'ns copsar de quina manera pretenia fomentar la religiositat sinó també per ser testimoni del món d'on prové, complementant així el panorama cultural del segle XV valencià. Havent estudiat la gènesi del text original, Ferrando explica que reflecteix el moment estilístic i espiritual en què va ser redactat, passant després per diferents vicissituds.

Clou el recull «El paper dels primers editors (1473-1523) en la fixació del català modern» (Caplletra 27, 1999, pp. 109-136). Ferrando considera el procés d'edició del llibre a les terres catalanes — on s'introduí via Itàlia — semblant al del context europeu. Com en terres italianes, el procés — segons la llengua i les

16 Potser val la pena d'afegir un exemple fefaent en aquesta línia, car Riquer definia l'estil de la Tragèdia de Lançalot de mossèn Gras — que hom ha denominat a vegades valenciana prosa-, com un estil condensat i sintètic degut a l'economia narrativa, fruit d'un resum argumental extraordinàriament comprimit; però escauria a més la concreció de llengua artitzada degut a la pruija estilística — prosa filigranada i artificiosa, que Gras mostra no ja al text de la narració, coincidint amb passatges del III del Curial—sinó també a la dedicatòria. 
temàtiques dels llibres editats als principals nuclis, Barcelona i València- estava lligat als cercles humanistes; aquests foren responsables de la normalització cultural fins que es perdé l'impuls davant l'empenta comercial del llibre en castellà. Es descriu per menut aquell procés, observant la tasca de correcció dels textos, comparant manuscrits i edicions, i remarcant «la fermesa de la consciència d'unitat lingüística», tot i que pesés el dialecte local; fets que, d'altra banda, atemperaren el tràngol — tan neuràlgic per a la llengua - derivat de la guerra civil i, encara, el de la integració dins la monarquia hispànica, de manera que «el català de la primera impremta, juntament amb la pervivència dels seus sòlids usos administratius, va ser decisiu per a mantenir viva la tradició cultural pròpia», p. 433.

Considero importants les reflexions sobre l'impacte de l'Humanisme en una nova sensibilitat lingüística, no sols per repercutir en una llengua més acurada sinó també per la regularització i modernització, ${ }^{17}$ influència que es manifesta bé en les edicions del segle XVI. Paral-lelament, hi aprecia un estil més natural i planer. I bé que es va començar a patir la pressió de la llengua castellana des d'aquest període, destaca positivament la funció que van tenir les edicions en la conservació de les grans obres del segle XV, així com el seu efecte integrador - suara esmentat - contribuint a proporcionar solucions unitàries, que evidenciaven que la unitat cultural de la terra — provincialitzada pels atzars de la història- es mantenia. Així, la impremta, durant els segles de decadència, fou un un reducte de la llengua culta, ${ }^{18}$ convertint-se en un referent. Es palesa també com el català «reeixí a sobreviure com a llengua de cultura» (p. 433), malgrat no haver estat llengua 'nacional'.

No voldria passar per alt una opinió d'accent més personal, al qual deixa cert lloc un gènere com el de la ressenya. Perquè, havent fet el seguit d'aquests treballs de 1'Edat Mitjana al Renaixement des de la llengua dels textos literaris, sobresurt l'harmonia amb els criteris que alguns hem mantingut des dels mateixos textos literaris (nota 10 supra); fet que no és estrany, car llengua $\mathrm{i}$ literatura van de la mà. I aquest comentari el podríem observar des de dues cares, de fet complementàries i que — crec que_s'avenen bé amb el feeling del llibre ressenyat:

D'una, es veu que les conseqüències esmentades suara pel corrent humanista, que es rep directament i ferventment des del bressol italià, actuen en l'àmbit de la cultura catalana sobre una ferma plataforma medieval (per exemple, sobre el debat metgià del Libre de Fortuna e Prudència); plataforma en bona part cancelleresca o influïda per la Cancelleria —o bé relacionada amb la monarquia, com deia el mestre Riquer-. I així com hem vist que això succeí de pri-

17 Impacte que he analitzat jo mateixa (al damunt d'investigacions riquerianes) des de l'altre extrem temporal, el de la primeríssima arribada de l'influx humanístic, a les acaballes del segle XIV.

18 Això durà fins el segle XIX, com podem corroborar des d'un gènere de tradició oral, empobrit i decadent per antonomàsia, el teatre hagiogràfic, que no assolí veritablement una métrica rica $\mathrm{i}$ un llenguatge culte fins a la peça de sant Martirià (titulada així per Comas i objecte de la meva tesi doctoral en 1978), obra de F. X. Butinyà que s’imprimí en 1871 (La venjança del martre). 
mer amb Llull (a Mallorca), més tard tingué lloc als tres nuclis urbans principals: Barcelona, Nàpols i València, que a vegades he assenyalat com eixos del fenomen humanístic de la cultura catalana. L'homogeneïtat cultural a què es refereix Ferrando, doncs, que adquireix força redoblada per la forta base lingüística, es veu multiplicada precisament gràcies als tres força dissemblants focus geogràfics, amb els seus respectius cercles $i$ a la varietat dels gèneres en què es manifestà. Circumstàncies aquestes de pes, que poden ajudar a explicar l'entitat que hom va donar a l'anomenat Humanisme català; car, per sobre de tota mena de diferències i peculiaritats, aquella empenta actuava sobre la mateixa llengua i cultura.

Denominació, concepte i moviment, el del nostre primer Humanisme, molt atacats i desprestigiats - sobretot un parell de decennis enrere-, però que admeté amb naturalitat un lingüista de l'altura de Badia Margarit, reforçant els grans pròcers de la tradició crítica cultural i literària, els Rubió i el mateix Riquer (1934). Per tant, és un altre motiu a celebrar que en aquest llibre es tracti de l'Humanisme així mateix amb naturalitat, com es fa arreu de les literatures europees (Humanisme francès, Humanisme castellà...), a pesar de les diferències pròpies de cada lloc i moment i de cada llengua. I encara, podríem dir altre tant quant al tractament del concepte de decadència en la cultura catalana, concepte discutit en els seus perfils i també en la mateixa denominació, però que Ferrando entèn en la llengua, com a la vegada cal entendre en la qualitat de la creació literària; en tots dos vessants, però, sense implicar un tall o interrupció.

De l'altra cara es pot constatar que, tant en l'aspecte lingüístic com en l'ideològic, les arrels d'aquesta excel-lent Edat Mitjana s'enfonsen en Llull, la figura d'aquesta etapa que té el ressò internacional més ferm. I així com fou capdavanter quant a la maduresa de la llengua, així també quant al pensament $i$ la seva expressió escrita, com de manera vistosa per l'altura, l'extensió i l'avançament d'idees testimonia el gran Llibre de Contemplació (ca.1274). I tot i que Llull no fou cap miracle — com hem dit més amunt-, tenia unes grandíssimes intel-ligència i personalitat; per tant, és coherent que suposés —així aquest Llibre - un punt de partida en la línia del racionalisme i del subjectivisme, en els quals s'aniria assentant arreu l'esdevenidor - Humanisme inclòs, com corrent immediat que ultrapassà el medievalisme-.${ }^{19}$ Aquests conceptes abstractes, però, no es poden demostrar a l'estil de les afortunades i valuoses anàlisis lingüístiques del nostre llibre; amb tot, al meu entendre, fent-hi engranatge, es recolzen mútuament.

Tanquem aquests comentaris agraint al Dr. Ferrando d'haver replegat aquests treballs per la utilitat que ens facilita la seva consulta, trobant-se ara de manera conjunta i a més unificats amb tot sentit. I si se'ns permet, al-legant de nou la ductilitat de les ressenyes, ens unim al tarannà d'homenatge a Germà Colón.

Junt amb això, volem insistir al fet que l'enfilall de la seva especialitat coincideix amb el del mestre Colón, motiu que ens porta de nou al pròleg, car

19 Cfr. la nota 3 supra. 
aquest és l'autèntic cor d'aquest llibre; cor que no sols té la comanda de preludiar sinó també la de sostenir qualsevol llibre que llueixi aquest noble apel-latiu. Encara més, aquesta continuïtat i bonhomia entre mestres i col-legues investigadors és el fil que ha d'informar i vertebrar pàgines i conceptes de qualsevol llibre que pertanyi al món acadèmic. Com es fa ací de manera modélica.

Júlia Butinyà

Universidad Nacional de Educación a Distancia juliabutinya@gmail.com

\section{Joan Veny. Un torrent de paraules. El lèxic de Joan Santamaria, Lleida: Institut d'Estudis Ilerdencs/Diputació de Lleida 2019, 287 pp. ISBN: 978-84-16452-58-3}

Comencem felicitant l'autor d'aquesta investigació d'arreplega lèxica, ressaltant que és la persona idònia i exacta per a portar-la a terme. Els qui coneixem una mica el seu currículum — que som la totalitat de generacions de l'àrea de Filologia Catalana en l'actualitat - entenem bé el seu interès per la temàtica triada - el lèxic de Joan Santamaria - com camp d'observació ple de fertilitat i rendiment lingüístic.

Aquest llibre té el doble carès d'obra interessant i d'eina útil, característica que dota a qualsevol publicació d'un aprofitament duplicat. Aquesta afirmació es pot comprovar a l'avançada, ja que havent-se exposat a la Introducció les dades necessàries per al seguiment de l'estudi —el buidatge del lèxic de Santamaria- des dels angles de la metodologia i la teoria, si anem tot seguit a l'Annex, al capdavall, hi obtenim ràpidament —a tall de fàcil instrument d'úsuna exposició pràctica i un resum força explícit del treball realitzat. I això, encara que un no s'hagi detingut a mirar el vocabulari, que és el gruix del llibre i on es satisfarà el lector disposat o preparat a seguir amb interès el recull lexicogràfic.

En aquest paràgraf gairebé hem donat les coordenades de l'obra, ja que es compon d'un lèxic, amb una introducció i un annex final. Altre punt subsidiari és la imprescindible bibliografia, de la qual cal dir que és l'ajustada i l'oportuna, afegint que seguirem ací les seves abreviatures, que són les usades normalment; així també ens servirem de les escaients per a les obres buidades de Santamaria, com: AP L'apòstol. Memòries del Dr. Verdós, 1927; QU Quatre titelles $i$ un ninot, 1926.

Es tracta, doncs, d'un Lèxic — distingint lèxic i Lèxic, com fa el Dr. Veny—, fruit d'un amant —-més enllà de l'àmbit de la gran Lingüística- de la Dialectologia i d'altres ciències afins a la Lexicologia; així com d'un bon coneixedor i valorador crític de l'autor estudiat: Joan Santamaria (1884-1955). Amb el benentès que el cos del llibre el constitueix el lèxic espigolat de les 
obres d'aquest escriptor lleidatà, segons els criteris selectius que se'ns declaren i d'acord amb les obres buidades.

Convé enumerar les parts de la Introducció, on se'ns donen les pautes que justifiquen l'edició i permeten d'entendre els continguts: Origen d'aquest Lèxic (pp. 11-12).- Esbós biogràfic. Obres (pp. 12-14). Valoració per la crítica del lèxic de Santamaria (pp. 14-17).- Objectiu d'aquest Lèxic (pp. 17-19).L'aportació dialectal (pp. 19-23).- Perfil sociolingüístic (pp. 23-24).- Obres despullades (p. 25).- Presentació de les entrades i Gratituds (p. 26).

Comencem els comentaris pel final, per l'Annex, donant així —com hem avançat - una idea de la utilitat del treball, ja que és on se'ns mostra aquesta d'una manera gràfica i resumida. Aquest apèndix darrer és un repertori -extret del repertori lèxic que integra el llibre-, al qual apareixen ordenats els vocables pels consabuts factors d'interès lexicogràfic, gramatical o dialectal: augmentatius (aviciadot), diminutius (bombeta), pejoratius (donatxa), superlatius (piíssim), compostos (suprahumà), derivats (abruptesa), onomatopeies (catacrac), eufemismes (caraina), vulgarismes (asteri), arcaismes (encontinent), cultismes (blandícia), neologismes (aurícula), mots de procedència forana: castellanismes (agarrats), gal-licismes (pendentif), anglicismes (stock), occitanismes (llausanger), llatinismes (ad hoc), italianismes (borsalino), i mots d'altres procedències (maorí). Les paraules són citades, com correspon, per ordre alfabètic i -ací- es donen sense especificar-ne accepcions (n'hem seleccionat generalment la primera paraula de cada punt).

Però a més n'hi ha d'altres seccions, que no acostumen a assenyalar normalment els diccionaris, almenys els d'ús, i que és on s'encabeixen els vocables més propis de Santamaria; així s'agrupen també: les variants formals (anjoví), variants morfològiques (aclaparanta), ultracorreccions (substràctum), incorreccions - i potser alguna errata - (lapariotomia), diatopismes nord-occidentals (a la fresqueta), diatopismes mallorquins (al·lot), altres diatopismes (abellitós) i mots nous no enregistrats o sense documentació (amostelat, glu-glu-glu, rosegaconfessionaris...). Amb aquests punts suspensius darrers volem indicar que és l'apartat principal en extensió — gairebé 2 pàgines de tot l'Annex, que en compta 7-; per tant, és l'agrupació prioritària per tal de mostrar la potencialitat creadora de llenguatge de l'autor i en consequiència és un motor primordial per a l'anàlisi efectuat.

Es fa evident que una llengua tan viva ofereix un bon panorama del vaivé sociolingüístic, el qual es pot apreciar partint d'una orella molt fina i d'uns coneixements idonis per part de l'estudiós, que ha de comptar, però, amb l'ocasió propícia per part d'un original que ofereixi la parla de manera distanciada o amb perspectiva i en diverses dimensions; tot això esdevé en un cas de diglòssia familiar que se'ns hi fa palès, tenint en compte el ressò del pas generacional en situacions familiars (p. 24). És a dir, que el cas en concret - que Veny extrapola molt adequadament a una altra generació posterior, la de la postguerra - d'una banda ho ha sabut obtenir gràcies a una aguda percepció i, d'una altra, li ho ha proporcionat el text de l'escriptor de Lleida. 
La llengua de Santamaria té la seva raó de ser, que Joan Veny perfila bé, acreditant d'haver-la constituilt encertadament un objecte a analitzar. En aquesta línia, recull testimonis com el de Farran i Mayoral, que explica que la tirada vocacional de l'autor, que el marca d'un accentuat cosmopolitisme i obertura a les diverses formes (pp. 19-20), conviu amb la petja de dialectalismes. Diatopisme que, si es deu inicialment al seu origen lleidatà, s'estén a llocs com Mallorca, on sojornà en la infància i adolescència. Així tenim l'ombra lèxica balear a Visions de Mallorca, mentre que a Visions de Catalunya hi ha una barreja que resulta de restar «extasiat davant les meravelles lingüístiques de la gent amb qui dialogava» (p. 21). De fet, Santamaria aplicava «una estratègia selectiva, tot renunciant a elements massa locals, vulgarismes, interferències, etc., en nom d'una llengua unitària i, alhora, participativa, com era el model de llengua del gran codificador» (p. 23).

A aquest model de llengua flexible i vivent jo també aspirava quan vaig recollir en un Diccionari d'autors del català modern (1994) els mots no enregistrats pel diccionari normatiu, aleshores «el Fabra»; en el meu cas — diferent, però no divergent-, m'hi vaig posar per un altre motiu, empentada pel fet que la llengua literària havia avançat en aquell sentit més que la codificada. Els punts en comú del nostre llibre amb el Diccionari suara esmentat s'afinen en registres com anar $i$ venir (usat per Gaziel) i anants $i$ vinents (per Santamaria). Tot i que no caldria fer-ne una anàlisi detallada, m'ha sobtat observar-hi sovint coincidències amb les mateixes accepcions assenyalades; així, en: catacrec (també utilitzat per Espriu), donya (per Sagarra), d'estranquis (Carner, Sales), glu-glu (Pedrolo, Rodoreda), mecatxo (Sales), redéu (Pere Quart), vano (Rodoreda). I bé que el comentari següent manqui de validesa objectiva per ser formulat de manera superficial, en passar sobrevolant pels mots recollits de Santamaria, m'atreveixo a dir que em sembla poder identificar alguns en la parla d'àvies (una barcelonina i altra gironina); així, amb gentota, homenàs, llenguota, manoi, marassa, matiné, o encara crec que podria recordar haver sentit al mercat de Banyoles, al Pla de l'Estany, uns quants decennis enrere, goret i nin.

El mèrit del nostre erudit i gran lingüista del segle XXI ha estat de valorar un autor lloat per la riquesa i exuberància lèxica per crítics que han apreciat el seu estil, qualifiquant-lo de «luxúria verbal» o de «barroc exultant» (Xuriguera); així també sobresurten d'altres judicis que afecten molt directament la llengua i especialment el lèxic (Montoliu, Tasis, Ruiz Calonja). Tot plegat, opinions que configuren el títol del llibre, el qual defineix la llengua de Santamaria com «Un torrent de paraules» (pp. 15-16).

Ara bé, no és una llengua modèlica, ans la llengua viva, copsada gràcies a l'estima i gravada a força d'inquietud. És lògic que en prengui passatges Joan Coromines —un dels reis del lèxic_-, com també havien fet Alcover i Moll. El primer el situa al DECat entre els escriptors menys personals, relativament poc fidedignes, però amb originalitat lexical i de projecció innovadora (p. 16).

Des d'un punt de vista lingüístic Veny reconeix «el valor de donar a conèixer mots no enregistrats fins ara o d'aportar documentació moderna de vocables que n'estaven mancats» (p. 17), no constant tampoc al $D C V B$, i a més, lèxic valuós per ampliar les àrees dialectals d'alguns vocables, fet que es pot con- 
frontar amb l'ALDC. En són ben eloqüents els freqüents mapes amb què ens ho il-lustra el nostre llibre (p. 63, canella; p. 87, despopar; p. 116, faldetes...).

Pot convenir de donar una mostra del funcionament del recull reproduint la presentació d'un parell d'entrades concretes, on certifiquem la documentació dels vocables. Veiem,doncs, que - després de la immediata determinació de la categoria gramatical i definició, amb l'accepció en què és usada, o bé l'equivalència - es reflecteix la cita amb indicació del lloc (obra i pàgina) d'on s'ha tret; seguidament s'anota si surt al DG (Diccionari Fabra, $1^{\mathrm{a}}$ o $2^{\mathrm{a}}$ ed.) i al DCVB; si cal ajustar-ho més, es dóna l'àrea dialectal, fent referència als mapes, i a l'últim s'adverteix si té o no documentació moderna, i en cas positiu, s'apunta l'autor/s:

CAPARRÓ m. Cap molt petit. «Mary, agenollada als meus peus, el caparró a la falda, els ulls tots parats d'encantament»AP 117; «Vèieu un cor de caparrons rossos» QU 68. DCVB. Doc: Verdaguer, Pons i Massaveu 1917.

CARAGOLAT, -ADA adj. Cargolat. «Els pèls vermells i caragolats de la testa del senyor Albiol» AP 175. DG-1 i DCVB (caragolar). Àrea: cat. occidental, balear, alguerès (ALDC, VII, m. 1564 caragol).

Havent fet aquest recorregut pel llibre de Joan Veny podem assegurar que ha complert els dos objectius que s'havia marcat, d'aplegar els mots amb interès per a la història de la llengua del primer terç del segle XX, així com els mots que revelen la força creativa de l'autor (p. 17).

En un gènere com el de la ressenya, en què hi ha més indulgència per a deixar aparèixer el jo, faré al-lusió també a l'autor de la Renaixença que va ser objecte de la meva tesi doctoral (Estudio histórico-literario de Francisco Javier Butinyà: 1834-1899), ja que en el grau que permetia la seva època manifestava ja en 1871 aquest desassossec lingüístic, segons acusen no sols les seves obres sinó també els criteris subjacents a l'epistolari amb l'historiador Pere Alsius. Els mots més particulars que empra també els recolliren els diccionaris d'Aguiló i d'Alcover i Moll, indicant a vegades com a font Butinyà o l'obra (Martirià); i encara Joan Solà en recollí alguns passatges relatius a la seva llengua a la Història de la Lingüística catalana. 1775-1900. Repertori crític (1999), com també l'ha considerat algun cop el Dr. Veny. Així també, com que som dins un entorn cronològic no gaire allunyat, pot interessar dir que algunes concurrències entre Butinyà i Santamaria palesen uns mots aleshores vius, com ara farfutalla (farfotalla en F. X. Butinyà en La venjança del martre (l'obra sobre sant Martirià), vocable també registrat pel DCVB i per l'Aguiló Dicc.); cal fer notar que els tres últims llocs registrats l'apliquen a persones, mentre que Joan Santamaria ho fa a més a coses.

Encara caldria comentar alguna cosa sobre Santamaria des del punt de vista literari, molt lligat al valor del lèxic. Ho han valorat crítics de diferents èpoques: de Montoliu (1933) a Leandre Amigó (1969), Fuster (1980) i, darrerament Martínez Gil (2017), segons puntualitza Veny (pp. 13-14), destacant sobretot les notes de vehemència verbal i de lirisme. 
Testimoniaré altres opinions més des de l'angle literari —el que em correspon més estrictament-, consultant dos de les principals fonts crítiques vigents de la Literatura. Una, l'encapçalada per Albert Hauf (Panorama crític de la Literatura Catalana), on, en el volum V — dirigit per Enric Bou-, Vinyet Panyella esmenta Santamaria entre els més representatius de la narrativa curta noucentista. A l'altra gran obra historiogràfica moderna (vol. X, pp. 50-51, de la Història de la Literatura Catalana, dirigida en la part moderna per Joaquim Molas), Carme Arnau li dedica un capítol, on deixa constància del fet que Santamaria jutja el seu moment com decadent, així com fa rellevar que el seu estil popular li va permetre arribar a un públic ampli; d'altra banda, entre les notes narratives fa sobresortir el sensualisme. Hi afegim que entre el conjunt de la producció d'aquest autor menciona totes les obres despullades pel Dr. Veny al seu recull lexicològic.

Un dels principals beneficis dels autors de la tirada de Santamaria —al marge que siguin d'estil exquisit o extraordinari- és que eixamplen la llengua o, millor dit, que creen llenguatge; val a dir, que enriqueixen les eines que té a l'abast el pensament humà; a banda del ressò en altres escriptors i en el seu entorn, és a dir, en els lectors. Així ho constatava jo mateixa, mitjançant el Diccionari d'autors esmentat, amb el lèxic de Josep $\mathrm{M}^{\mathrm{a}}$ de Sagarra — de manera molt accentuada front als altres autors-, que és un autor tot just d'estil també molt popular. Reflexions semblants es deriven normalment d'experiments lèxics d'aquest tipus $i$ donen peu a divertits malabarismes, a què haurà arribat sens dubte Joan Veny, com em va passar a mi mateixa amb el meu estudi. Se'n poden fer encara estimacions des d'un caire més seriós: "Obras como esta, aparte de su valor como suplementos de los diccionarios corrientes, constituyen un excelente ejemplo, infrecuente en nuestro país, de la necesidad de la documentación como base metodológica en lexicografía» (citació de Gregorio M. Guerrero, «Lingüística española actual» XVII/1, 1995; fa referència al meu treball, però l'aporto tanmateix perquè és plenament vàlida per al llibre que estic ressenyant $\mathrm{i}$ que li projecto de cor ja que expressa el meu parer de manera millor de la que jo ho sabria fer).

Faré finalment un salt mortal saltironant entre segles. I així, passant al segle XV, observem que l'autor del Curial — sembla clar, gràcies a la descoberta d'Abel Soler, que fos Enyego d'Àvalos als dos primers llibres; i anònim que el Dr. Veny ha estudiat molt bé- mostra així mateix un gran dinamisme lèxic. I si passem pel P. Butinyà — tria que faig, malgrat ser-me parent, pel fet d'haverlo esmentat abans - tenim el mateix cas. Com també succeeix amb Joan Santamaria, una mica més proper temporalment. Tots ells, autors de diferents nivells i força creativa, de gèneres i segles variats. Però tots emportats per la «curiositat lingüística». I si hi incorporem l'autor d'aquest llibre, que pateix la mateixa curiosa inquietud, ens la trobem estesa fins al nostre temps. Beneïda curiositat, de què ens beneficiem tots.

Júlia Butinyà

Universidad Nacional de Educación a Distancia juliabutinya@gmail.com 
